\title{
Noviolencia como alternativa de resistencia en Chiapas, México: el caso de Las Abejas de Acteal
}

\author{
Leonardo Nicolás González Torres \\ Universidad Autónoma de Aguascalientes, San Cristóbal de Las Casas, México. \\ Email: psileogonzalez@gmail.com
}

\author{
María Eugenia Patiño López \\ Universidad Autónoma de Aguascalientes, Aguascalientes, México. \\ Email:mepatino@correo.uaa.com
}

\begin{abstract}
Resumen: ${ }^{1}$ A partir de la pregunta por la posibilidad de que la noviolencia pueda servir como categoría analítica de los procesos de resistencia en Chiapas, México, en este artículo se aborda el caso de la organización indígena y pacifista Las Abejas de Acteal. Retomando algunas investigaciones previas sobre el tema y los comunicados de la organización, se exploran las relaciones entre la noviolencia y la resistencia que dicha organización ha realizado entre los años 2009-2015; atendiendo fundamentalmente a la relación entre medios y fines en su lucha, la búsqueda de autonomía y justicia y, el papel de la memoria. Se concluye que los fenómenos de resistencia indígena en la zona, requieren un abordaje diferenciado y se resalta la potencialidad que la teoría ético-política de la noviolencia puede tener para el estudio de la resistencia indígena en Chiapas.
\end{abstract} Acteal.

Palabras clave: Noviolencia; justicia; resistencia indígena; Las Abejas de

\section{Nonviolence as an alternative of resistance in Chiapas, México: the case of Las Abejas de Acteal.}

\begin{abstract}
From the question of the possibility that non-violence could serve as an analytical category for studying resistance processes in Chiapas, Mexico, the case of the indigenous and pacifist organization Las Abejas de Acteal is resumed in this article. From previous research on the topic and the public press dispatches of the organization, the relationship between nonviolence and resistance the organization has made in the years 2009-2015 is explored; attending mainly the conection between means and ends in their struggle, the search for autonomy and justice, and the role of memory. We conclude that the phenomena of indigenous resistance in the area requires a differentiated approach, and we highlight as well the potential that ethical and political theory of non-violence may have on the study of indigenous resistance in Chiapas.
\end{abstract} Acteal.

Keywords: Non-violence; justice; indigenous resistance; Las Abejas de 


\section{A não-violência como uma alternativa de resistência em Chiapas, México: $O$ caso deLas Abejas de Acteal}

Resumo: A partir da questão da possibilidade de que a não-violência pode servir como uma categoria analítica de processos de resistência em Chiapas, no México, neste artigo éretomado o caso da organização indígena e pacifista Las Abejas de Acteal. Revisitando algumas pesquisas anteriores sobre o assunto e os comunicados da organização, exploram-se as relações entre a não-violência e a resistência que dita organização tem feito entre os anos de 2009-2015; principalmente sobre a relação entre meios e fins na sua luta, a busca por autonomia e justiça eo papel da memória. Conclui-se que os fenómenos de resistência indígena na área, requerem uma abordagem diferenciada e se salienta o potencial que a teoria éticopolítica da não-violência pode ter para o estudo da resistência indígena em Chiapas. Acteal.

Palavras-chave: Não-violência; justiça; resistência indígena; Las Abejas de

$* * *$

\section{Introducción}

A menudo, un acercamiento al estudio de la resistencia indígena en la región de Chiapas, y específicamente en la región de los Altos², puede dar al investigador una imagen de conflicto y violencia constante. A partir de una inmersión en el estado del arte sobre el tema, vemos que la literatura especializada abunda en el estudio de temáticas como: el conflicto entre las comunidades y el Estado (Arias, 2008); las dificultades en alcanzar la paz (Moreno y Miranda, 2003); los conflictos políticos y sociales, etc. (Guillén, 2003). Ello se ve reflejado también en el estudio de la resistencia civil, que entendemos como "una manera de gestionar los conflictos sociales y de poder frente a la opresión o la tiranía, para conseguir obtener o consolidar derechos y libertades públicas” (López, 2012a: 44) la cual, observamos, ha sido generalmente estudiada en relación a la violencia, como categoría predilecta de análisis.

Si bien compartimos la importancia del estudio de la violencia en el contexto de la resistencia, creemos que, el énfasis puesto en dicha temática implica el riesgo de perder de vista aquellas manifestaciones de procesos de paz positiva (Galtung, 1969) presentes en ella. Vemos en esta situación que los investigadores han emprendido en algunos casos el estudio de los procesos de violencia y conflicto ligados a la resistencia indígena en la zona y en otros, de lo que Galtung (Ídem) ha denominado la paz negativa, es decir, la paz como la ausencia de guerra.

Siguiendo a Muñoz y López (2000) existen, al menos, dos elementos explicativos de la situación descrita: i) por un lado, los conceptos de paz, violencia y conflicto son difíciles de definir debido al amplio y difuso contexto teórico en el que se los suele plantear; y ii) la escasa problematización que con frecuencia se produce de los procesos de conflicto, que conlleva a pensarlos en términos de todo o nada, es decir, dando por sentado que la 
violencia y la paz son dos procesos absolutos, pasando por alto de este modo, el papel de los actores sociales en empresas de paz.

En consecuencia, para intentar visualizar las empresas que contribuyen a la paz en contextos de conflicto y violencia, será necesaria una perspectiva teórica que tome como punto de partida la potencialidad de los seres humanos para la paz. El concepto de paz imperfecta, base sobre la cual planteamos la posibilidad de discutir la resistencia noviolenta, es un ejemplo de ello. En relación al mismo, afirman Muñoz y López (2000:48): “Es por ello que preferimos hablar de una paz imperfecta porque no es total ni está absolutamente presente en todos los espacios sociales, sino que convive con el conflicto y las distintas alternativas que se dan socialmente a éste para regularlo.”

Sin embargo, no diremos que la dinámica indígena chiapaneca está exenta de lucha ${ }^{3}$. Como el lector podrá comprobar en lo sucesivo, sostendremos que la resistencia indígena ante las políticas neoliberales y el colonialismo -entre otros- ha sido desde la conquista un proceso constante. ¿Cómo salir entonces del atolladero que implica intentar visibilizar la paz en el enfrentamiento, en la disidencia y en definitiva, en la resistencia? Es en este sentido que pensamos que el concepto de noviolencia (López, 2004) ofrece amplias posibilidades a la hora de proceder al estudio de tales fenómenos en la región.

Valga antes sin embargo, una aclaración para ubicarnos conceptualmente. Cuando nos referimos a noviolencia, compartimos con López (2012b) y Ameglio (2002) que la negación de la violencia puede dar una idea equivocada de su acepción. Por ello, al hablar de la resistencia noviolenta hablaremos de una muy activa lucha, que se expresa en: principios, fines y estrategias alejados de la violencia. La entendemos por tanto como "un conjunto de formas y procedimientos de lucha, pugna, forcejeo y hasta de guerra político-social” (López, 2004:12), que funge como acción alternativa al poder hegemónico; que implica una oposición a la violencia y también un rechazo a usarla.

Ahora bien, desde ésta perspectiva, que concibe a la noviolencia como una forma alternativa de lucha frente a la hegemonía belicista, será importante dilucidar un último punto: ¿Es posible hacerlo desde una perspectiva que contemple la agencia de aquellos actores sociales que buscan no sucumbir ante el uso de la violencia, proponiendo modos alternativos de resistencia y vida? Pensamos que, desde una perspectiva que busque visibilizar la noviolencia, es de utilidad emprender el análisis de casos concretos en los que ésta se manifiesta.

Si bien, como afirma Ameglio (2002:185) "sabemos que en nuestro país hay y ha habido siempre una gran cantidad de movimientos y organizaciones que han realizado luchas no-violentas”, retomamos en el presente trabajo el caso de la organización Las Abejas de Acteal, que surge en la región de los Altos de Chiapas, México, en el año 1992 y realiza desde dicha 
fecha una labor de defensa de los derechos de los pueblos indígenas y humanos. Sus vínculos con el pacifismo, en etapas iniciales de su labor, han sido estudiados en Tavanti (2003). Sin embargo, creemos que sus posteriores logros en términos de resistencia noviolenta no han sido analizados. Pensamos que su tratamiento, abonará a favorecer la discusión sobre la manera en la que en diferentes lugares del mundo y desde luchas diversas, se pone en práctica el mismo principio ético de la noviolencia.

Antes de iniciar nuestra discusión, y como modo de introducción para el lector que no esté familiarizado con ella, diremos que la organización cobra notoriedad nacional e internacional a partir de -al menos- tres elementos principales: i) la masacre de Acteal $^{4}$ en 1997, donde fueron asesinados a manos de grupos paramilitares 45 indígenas tsotsiles de la organización, en el contexto de los desplazamientos y paramilitarización producidos en torno al conflicto armado entre el Ejercito Zapatista de Liberación Nacional ${ }^{5}$ y el Estado mexicano desde el año 1994; ii) la labor de denuncia de la violencia hacia los pueblos organizados o en resistencia y por la impunidad con que ha sido tratada la masacre antes referida; y, iii) los puntos de encuentro de dichas empresas (objetivos, métodos de lucha, etc.) con la noviolencia, aspecto éste sobre el que recae el interés del presente artículo.

A continuación, se tratará la relación entre la resistencia y noviolencia en la organización mencionada, teniendo en cuenta seis bloques analíticos; en el primero de ellos se abordan algunos factores que permitan contextualizar la presencia de la resistencia indígena en México y, específicamente en Chiapas; en el segundo se tratará el surgimiento de la resistencia noviolenta en la Organización Las Abejas de Acteal; posteriormente, en el tercero, nos detenemos en reflexionar sobre papel de los medios y fines en dicha resistencia; en el cuarto abordamos algunas consideraciones sobre los límites a la obediencia y su relación con los objetivos de la organización; en el quinto apartado nos abocamos a consideraciones en relación a la búsqueda de autonomía y reconstrucción social; en el sexto abordamos el papel de la memoria y sus relaciones con la noviolencia y, en la última sección, presentamos algunas reflexiones finales a modo de conclusión.

\section{Resistencia indígena en México: algunas claves para la comprensión de su emergencia}

Desde mediados del siglo pasado a nuestra fecha, las organizaciones indígenas han atravesado por una constante reconfiguración de su papel ante el Estado post colonial. La resistencia indígena en muchos lugares de México se ve reflejada en planteos que cuestionan las políticas neoliberales -de explotación de recursos naturales, desplazamiento por megaproyectos, imposición de un modelo hegemónico de vida, etc.- que atentan contra su patrimonio cultural y material (Sandoval, 2010). 
Para comprender dicha resistencia, es necesario tener en cuenta a los procesos colonizatorios a los que han estado sujetos. La colonización de los pueblos indios en México, según Bonfil (1990), parte de una condiciónhistórica que no puede pasarse por alto si se pretende entender su situación presente. El "hecho de que durante quinientos años han sido los colonizados" (Ibid:48), ha traído aparejado el despojo cultural y material de los pueblos mencionados, "ha provocado formas muy variadas de resistencia, ha intentado por todos los caminos asegurar la sujeción del colonizado, más efectiva cuanto más se convenza éste de su propia inferioridad ante el colonizador"(Ibíd.: 49).

Lo mencionado es también observado por Orozco (2008), para quien la llegada de los conquistadores españoles y la colonización emprendida por éstos, reconfiguró la condición de identidad de los pueblos originarios, pasando a partir de ella, a ser considerados indios. Dicha reconfiguración trajo aparejada hasta la fecha, una serie de desacuerdos entre el Estado y las organizaciones indígenas en torno al modo en el que entienden sus derechos y obligaciones. Para muchas organizaciones indígenas la resistencia fue el modo no solo ético, sino natural de respuesta ante un régimen que pasaba por alto su historia y sus derechos como pueblos originarios.

En síntesis, si se desea comprender dicha resistencia es importante plantear el hecho de que ella es un intento de recuperación y revalorización del patrimonio indígena, posterior a una historia de despojo. Frente al mismo, a partir de los ochenta y principios de los noventa del siglo XX, comienzan a surgir en México organizaciones independientes como:

La Unión de Comunidades Indígenas de la Zona Norte del Istmo (Ucizoni); la Unión de Comunidades Indígenas de la Región del Istmo (UCIRI); la Unión de Campesinos Independientes 100 Años (UCI 100 Años); y la Asamblea de Autoridades Mixe (Asam). Varias organizaciones independientes surgieron en otros estados: la Organización de Médicos Independientes del Estado de Chiapas (OMIECH) y la Organización de Representantes Indígenas del Estado de Chiapas; en el Estado de Hidalgo, el Frente Democrático "Emiliano Zapata”, en México oriental (FDOMEZ); y en el Estado de Guerrero, el Consejo de los Pueblos Nahua de Alto Balsas. (Bartra y Otero, 2008: 413)

Ello da cuenta de una creciente convocatoria de proyectos de origen indígena en México, así como de la emergencia de nuevos sujetos sociales (Touraine, 1997) en defensa de sus intereses étnicos y políticos, que cuestionan a la sociedad y el Estado sobre el dispositivo de segregación. Éste será uno de los elementos que propician que Chiapas - estado, en conjunto con Oaxaca, donde se concentra la mayor cantidad de población hablante de lenguas indígenas en México ${ }^{6}$ - se convierta en un espacio privilegiado de disidencia. Este estado, será el terreno en el que la resistencia se dejará sentir con mayor fuerza en los años noventa del siglo pasado, generando la 
emergencia de movimientos que en su denuncia exponen el abandono en el que vivían, y viven actualmente muchas comunidades indígenas.

Uno de los elementos a considerar en este despertar de los movimientos, en el caso de Chiapas, es la labor de la Iglesia católica en la zona dirigida por el obispo Samuel Ruiz, de la diócesis de San Cristóbal de Las Casas en los años 1959-1999, la cual se vuelve sensible ante el hecho de que en México "había un funcionamiento indebido de las estructuras sociales, que expulsaba fuera a una inmensa cantidad de mexicanos, carentes de todos los derechos. Pero el indígena estaba en una situación peor: porque estaba fuera, incluso, de la misma marginación” (Fazio, 1994:109). Recogiendo los planteos de la teología de la liberación, pero preocupado más por una puesta en práctica que por una ontología de la misma y adoptando una opción preferencial por los pobres, los esfuerzos del entonces obispo se dirigen a generar en el interior de la diócesis -a través de diáconos, agentes pastorales y equipo diocesano en general- y en los habitantes de las comunidades indígenas, un proceso de concientización sobre la opresión política, cultural y económica bajo la cual vivían.

Dicho proceso supuso un parteaguas a partir del cual diferentes actores comenzaron a incorporarse a movimientos sociales que desbordaron los planteos religiosos y devinieron en la toma de acciones en la arena política. Todos ellos recogieron a su modo, la demanda indígena de tierra, justicia y respeto a sus derechos culturales; sin embargo - y aquí se encuentra el centro de nuestra discusión- no todos lo hicieron de la misma manera.

De lo antedicho se desprende la importancia que la organización Las Abejas tiene como referente empírico del modo en que la resistencia se combina con el compromiso ético de la noviolencia. Si bien su faceta pacifista ha sido explorada en Tavanti (2003) y su compromiso por la paz es relativamente conocido en México (Ameglio, 2002), creemos que sus actuales acciones y planteos así como su relación con la noviolencia, no han sido del todo exploradas. A modo de profundizar en la temática que nos convoca, nos proponemos tratar y discutir a continuación el caso de dicha organización, lo cual esperamos siente las bases para la comprensión de la manera en que la resistencia civil noviolenta y la búsqueda de autonomía son prácticas vigentes en el México actual.

\section{Organización Las Abejas de Acteal: de la violencia a la noviolencia}

La organización Las Abejas nace en el año 1992, y su sede se encuentra actualmente en la localidad de Acteal centro, ubicada el municipio de Chenalhó, perteneciente al estado de Chiapas. Fue formada, en un principio, por catequistas indígenas de la misma diócesis de San Cristóbal de Las Casas, que en conjunto con personas de comunidades aledañas, se 
convocaron ante la necesidad de protestar y movilizarse en contra de la injusticia imperante en la zona. Tras el éxito obtenido por haber logrado el cumplimiento de algunos derechos -a través de métodos de persuasión y protesta noviolenta (Sharp, 1988) como procesiones y marchas- deciden llamarse "Las Abejas", nombre alegórico que describe a dichos animales que: trabajan en conjunto, se protegen, están conectados y tienen una reina a la que sirven (Orozco, 2008). Sin embargo, su notoriedad se debe fundamentalmente a dos elementos: el primero de ellos es la masacre de Acteal; el segundo, su reclamo noviolento de justicia y -actualmente- las acciones desarrolladas a fin de lograr una consolidación de la autonomía.

Para comprender las causas de la masacre mencionada, es necesario retomar como antecedente al levantamiento del EZLN el primero de enero de 1994; momento en el cual Las Abejas prefirieron mantenerse como movimiento civil aduciendo que, si bien simpatizaban con los ideales del ejército insurgente, no respondían a sus órdenes. Afirmaron: "tenemos que hacer la lucha pacífica y no con armas. Somos hermanos de ellos y para los dos nuestro principal enemigo es el gobierno y las autoridades priistas ${ }^{7}$ " (Hernández, 2012: 103). Intentando detener la guerra y palear sus consecuencias, Las Abejas utilizaron métodos de intervención no-violenta (Sharp, 1988), creando campamentos de refugio para desplazados por el conflicto, participando en interposiciones noviolentas ante el ejército y realizando ayunos masivos.

No obstante, siguiendo a Baucells y Hava (2007), el levantamiento trajo aparejada una estrategia contrainsurgente que buscó asediar militarmente no sólo al ejército mencionado, sino también a las organizaciones y comunidades indígenas afines a su ideología. Como consecuencia, en los años previos a la masacre, la zona de Chenalhó se caracterizará por una creciente presencia militar y paramilitar que tuvo como uno de sus efectos más cruentos, la masacre de Acteal:

Aquí la acción paramilitar tuvo una expresión culminante en la población de Acteal, cercana a San Pedro Chenalhó, donde el 22 de diciembre de 1997, fueron asesinados 49 indígenas tsotsiles que se encontraban en una ermita, después de tres días de ayuno y oración por la paz ${ }^{8}: 19$ mujeres, 8 hombres, 14 niñas, 4 niños y 4 fetos que junto con sus madres fueron brutalmente asesinados, además de 17 heridos, por el grupo paramilitar priísta que actuaba en la región (Baucells y Hava, 2007:123-124)

A partir de la masacre surgen, según Tavanti (2003), dos interpretaciones antagónicas sobre su origen. Para sectores vinculados al gobierno, la masacre fue producto de conflictos comunitarios; para las ONG's en contacto con la organización, la masacre fue producto de una estrategia contrainsurgente. Por su parte Hernández (2012: 101), asevera que "la mayoría de quienes fueron asesinados en Acteal eran integrantes del grupo Las Abejas. Comprometidos con la lucha democrática y anticaciquil, rechazaban la vía armada y estaban firmemente comprometidos en la búsqueda 
de salidas pacíficas al conflicto". Realizando un recorrido por las causas e implicaciones políticas posteriores a la masacre, el autor afirma que, el asesinato pretendió servir de ejemplo a todas las comunidades indígenas que no se alineasen a sectores vinculados con el oficialismo. Chenalhó era un centro estratégico del zapatismo por su ubicación; por otro lado, "en San Pedro Chenalhó, como en otros muchos municipios de Los Altos, existió, desde antes de la insurrección de 1994, un proceso organizativo de las comunidades indígenas de gran aliento, conducido por el zapatismo" (Ibíd.: 102). Esta organización e independencia de las comunidades que intentaban re organizarse y autogobernarse, fue lo que produjo el surgimiento del grupo Las Abejas.

Posteriormente a la masacre, y hasta la fecha, Las Abejas han rechazado en diferentes ocasiones cualquier tipo de represalia violenta contra los victimarios. A partir de la masacre se constituyeron como una organización que, desde la sociedad civil organizada, busca la paz y la justicia; para ello crearon comisiones dentro de la organización, destinadas a dialogar con el Gobierno y a atender las problemáticas de desplazados ${ }^{9}$ por la guerra. En dicho proceso, contaron con la ayuda de la diócesis de San Cristóbal de Las Casas y el apoyo de las ONG's.

Desde el año 1998 al 2009, al inicial pacifismo y anti armamentismo se irán sumando otras formas de acción, tendientes a visibilizar la impunidad por la masacre y generar una presión política para conseguir justicia plena. Éstas, comprendidas en lo que Ameglio (2002:118) denomina informaciones y diálogo, buscaron "llegar a acuerdos pactados en encuentros con el adversario, y a la vez informar a sectores amplios de la población acerca del conflicto con el fin de construir posibles aliados". Algunas de estas acciones fueron: la realización de comunicados, radiodifusión, videos, además de las labores de negociación para pactar el regreso de los desplazados a sus comunidades de origen, entre otras.

\section{Tenemos que hacer la lucha con medios pacíficos: hacia una política sin violencia.}

En los años venideros, la relación con el Estado oscilará entre el reclamo de justicia hacia las autoridades y la expectativa, por parte de la organización, de su cumplimento efectivo. Apelando a la persuasión y protesta (Sharp, 1988), como modo de presionar a las instituciones, se realizaron los primeros comunicados y se dio lugar a acciones públicas simbólicas como la conmemoración pública de la masacre de Acteal ${ }^{10}$. Asimismo, para llevar su mensaje hacia otros espacios la organización, vinculando el arte con la resistencia noviolenta, creó el Coro de Acteal ${ }^{11}$. Todos los anteriores, recursos que siguen utilizando hasta la fecha.

Sin embargo, y en contra de lo esperado, en el año 2009 se produce la liberación de los acusados y procesados como actores materiales de la 
masacre de Acteal (Orozco, 2014). Con lo mencionado, inicia un proceso reflexivo dentro de la organización que comienza a desconfiar de la capacidad y voluntad de las autoridades en el cumplimiento de sus garantías. El centro de derechos humanos Fray Bartolomé de Las Casas (2015:34), afirma:

Desde el inicio de las investigaciones las autoridades estatales mostraron su falta de voluntad para investigar los hechos, lo que dio como resultado una inadecuada sanción y una inexistente reparación de los daños a las víctimas [...]. Ante este patrón de impunidad el caso fue admitido por la $\mathrm{CIDH}^{12}$ en noviembre de 2010 y se encuentra en la etapa de estudio sobre el fondo.

Lo mencionado dará pie a la emergencia de una paradoja en el previo conflicto, a saber: ¿Cómo pedir justicia a quien se considera un victimario? En consecuencia, se produce un cambio en los objetivos de la organización y en los roles previamente ocupados en el conflicto; el sistema de justicia federal se convierte en un adversario y la organización pasa del reclamo por justicia, a la lucha contra un sistema de justicia al que considera inmoral. A la previa lucha por la visibilización de la impunidad por la masacre, se suma un reto aún mayor que -desde la noviolencia- podemos traducir en el inicio de un forcejeo moral, una pugna, $\mathrm{y}$ - en definitiva- una lucha por cambiar el modo en que se hace justicia y los objetivos del proyecto de gobierno imperante. Dicho reto ha implicado, sin embargo, un desafío: luchar sin violencia, o, parafraseando a López (2012a) hacer política sin violencia y sin matar.

En este punto es necesario analizar un asunto que no es menor para la práctica de la noviolencia, es decir: el modo en que la resistencia y la lucha pudieran ir de la mano de la paz. Nos referimos a la cuestión de los fines de la resistencia y los medios para conseguirlos. ¿Se puede obtener paz, mediante el uso de la violencia?

¿Qué dice la noviolencia? Una de las cuestiones que más se remarca es que un determinado fin no se obtiene mediante cualquier medio; y, así como en cada medio que se usa está implícito un determinado fin, si se usan determinados medios o se realizan ciertas acciones sólo se podrán obtener unos fines y no otros. En consecuencia la máxima atribuida a Maquiavelo «el fin justifica los medios» es rechazada porque si se pretende conseguir un fin será necesario usar sólo algunos instrumentos bien precisos adaptados a esa obtención y no otros, o sea, que no todo sirve y que no todo es eficaz, además de que puede ser inmoral, para obtener un fin (López, 2012b:31).

Lo mencionado, permite comprender la causa por la cual se ha definido a la noviolencia como una teoría ético política (López, 2012b); es política porque, para ella el poder, su uso y ejercicio son una preocupación central. Pero también es una ética, en el sentido de que se preocupa por discutir y problematizar el modo en que las acciones políticas pudieran o no, estar 
orientadas al bien. Por ello, cuestiona al poder desde la moral; por ello, es una política alternativa.

En este sentido, el rechazo de la organización Las Abejas a participar con las armas en el conflicto entre el Estado y el EZLN en el año 1994 y a posteriori, tiene como causa un impedimento moral. El principal de ellos, ha sido su convicción de que la vida es sagrada y dada por Dios y sólo éste puede quitarla. Por ello llaman a las víctimas “mártires” y han constituido como principio central de la organización el respeto a la vida, afirmando: "La muerte de nuestros hermanos cumplieron con el principio más difícil de nuestra organización, que es el de “defender la vida y no quitarla; y cuando es necesario, entregarla” (Comunicado 22 de diciembre del 2012 ${ }^{13}$ ). Por la misma razón, se han negado a la venganza y han buscado justicia.

No son los fines los que no comparten con el EZLN, sino los medios por los cuales han intentado conseguirlos. La lucha contra el sistema se ha apuntalado en los últimos 18 años desde la masacre, en la fuerza moral y no en la física. Ello ha implicado para la organización, el ejercicio del diálogo y la creatividad, dos de los valores de la noviolencia (López, 2012b), en búsqueda de modos éticos de lucha. Lo mencionado se dejará ver en etapas posteriores al año 2009, período en el cual dichos elementos se combinarán -en el contexto de la confrontación con el gobierno- con estrategias destinadas a cambiar las relaciones con el poder.

\section{Los límites de la obediencia: mártires de Acteal y compromiso ético.}

¿Qué implica obedecer? ¿Qué condiciones necesita la autoridad para ejercer el poder? Las anteriores no son preguntas desvinculadas de la noviolencia; por el contrario, se encuentran estrechamente ligadas a ella y han dado lugar a muchas luchas sociales que, identificadas generalmente con Gandhi, Luther King, Mandela, entre otros, tienen -como pretendemos analizar- correlatos también en otros lugares del mundo. Plantearlas, visibilizarlas y comprenderlas forma parte de un proceso de construcción de una historia de la noviolencia. La misma, da cuenta de no escasos momentos en los cuales diferentes actores sociales han enfrentado la ley buscando cumplir con aquello que consideraban justo. Ello ha dado, por supuesto, no pocos problemas a quienes, desde la noviolencia, se han contrapuesto al poder. Sin embargo, algunos de los planteos de la noviolencia al respecto, nos permiten comprender la causa de dichas empresas.

Para López (2012b), el poder se sustenta en el consentimiento y el apoyo que los ciudadanos puedan darle al mismo. La autoridad depende, en otras palabras, de que se la considere como tal.Sharp (1988), retomando a Maritain, define a la autoridad como: "el derecho a mandar y dirigir, a ser escuchado y obedecido por otros” (Ibid: 23). Cuando se cuestiona la auto- 
ridad, se cuestiona también el derecho que tiene dicha autoridad a mandar y, la obligación del pueblo a obedecer.

López (2012b:53) afirma en relación a la obediencia que: "para la teoría ético política de la noviolencia, tanto el gobierno como el sistema dependen de la buena voluntad de los ciudadanos, de sus decisiones y de su apoyo [...]. El verdadero poder, depende de la gente, de los ciudadanos, es pluralista y no está concentrado". En ese sentido, señala el autor, la obediencia es esencialmente voluntaria y por ello, el consenso puede ser retirado. Para la noviolencia los deberes concretos de los ciudadanos hacia el Estado tienen límites. Los mismos, pueden tener como causas motivaciones morales, políticas, religiosas, etc. Las Abejas han afirmado:

“¿Y quién va a venir a defender nuestra madre tierra de las garras y de la avaricia del monstruo? Nadie, nadie más que nosotros mismos. Ghandi decía: cuando una ley es injusta, lo correcto es desobedecer. Nosotros como pacifistas defenderemos nuestra madre tierra, con métodos no violentos, así como; la desobediencia civil, así hemos venido practicando desde hace más de 22 años” (Comunicado, 22 de febrero del 2015).

En Las Abejas, la retirada del consentimiento hacia el gobierno, surge como consecuencia de un llamado interno a cumplir con la búsqueda de la justicia y la verdad en muchos planos, pero sobre todo, respecto de la impunidad por la masacre de Acteal; es rebeldía que nace del descontento, pero también de un profundo sentido del deber. Tolerar la injusticia, se contrapone con la memoria de las víctimas de la masacre y la vulneración de sus derechos. Por esa razón, los mártires de Acteal, como se llamará a las víctimas de la masacre a partir de la misma, se constituyen como un motor de lucha que refuerza, desde ese año, su vocación contestataria. Aceptar la impunidad de la masacre es no cumplir con los masacrados, es olvidar y pasar página a la violencia y a la muerte. Por ello, a partir de la masacre de Acteal y -reforzado ello- por la liberación de paramilitares en el año 2009, las obligaciones morales hacia el Estado son cuestionadas, como fruto de la desconfianza en su capacidad de proteger sus derechos humanos y culturales. Sobre este nuevo posicionamiento, el gobierno se convierte para la organización en una entidad sin autoridad y en consecuencia, se reúsa a cooperar con el mismo.

A partir de ello la autonomía será una preocupación central para Las Abejas, que deja traslucir su rebeldía y búsqueda de alternativas ante la situación descrita. Lejos de una actitud pasiva y obediente - la cual según Ameglio (2002) encuentra su reproducción en el hecho de ser premiada y presentada como una virtud; por ser lo que todos hacen y por miedo al castigo- la organización se desmarca del proyecto civilizatorio dominante en el México actual y marcha, hacia un proyecto de vida alternativo. Dicho proyecto, apuntalado en valores y objetivos como la otra justicia, el autogobierno, la autonomía material, entre otros, implica un cambio cultural. Ello en el sentido de que dicha desobediencia "corroe al poder con la 
resistencia cultural, que va creando otra cultura alternativa [... ] se construyen una vida independiente de la sociedad y estructuras paralelas una segunda cultura” (Ibíd.:130).

En ese cambio pueden verse algunos elementos y puntos de encuentro con el gandhismo. Uno de ellos es que, para Las Abejas, la desobediencia tiene como fin la independencia o autonomía- como ellos mismos la llaman-, y otro que ya se ha señalado, que dicha independencia se asienta en la construcción de alternativas que excluyen la violencia como una opción de lucha. Si bien no podemos extendernos exhaustivamente en el análisis y discusión de dicho proyecto, diremos que es un proyecto de autogobierno no consolidado sino en construcción. Sin embargo, creemos que es posible poner en la mesa de discusión algunos de sus elementos constitutivos más importantes.

\section{Hacia la consecución de autonomía y la reconstrucción social}

Para los pueblos originarios y organizados de México la autonomía implica vivir de acuerdo a sus propias costumbres y en el territorio que han habitado sus antepasados. Como producto de la implementación de políticas neoliberales que, desde la década de los noventa, han puesto en riesgo su patrimonio cultural y material, la búsqueda de autonomía ha devenido en frecuentes posicionamientos de resistencia. Sin embargo, el carácter distintivo que tiene en Las Abejas la misma se asienta en un proceso constructivo diferente al de otros grupos, por ejemplo el EZLN, ya que la organización, busca su conquista a través una fuerza moral y cooperativa, que prescinde de las armas como recurso.

Dicha autonomía tiene como fundamento en Las Abejas el valor de la tierra, que en la tradición maya involucra su respeto y conservación por ser el sustento material y alimento para los pueblos originarios. Por esa razón, uno de los aspectos que tienen centralidad en su planteo es la lucha por la propiedad de la misma. Aunado a ello, para la cosmovisión tsotsil, la tierra se compone de lugares sagrados; verdaderos enclaves espirituales que deben ser protegidos ante cualquier amenaza. De ahí su rechazo a los megaproyectos y las políticas económicas neoliberales y por ello los puntos de encuentro entre su lucha y las inquietudes del ecologismo:

"Es por eso que lo que hacemos de por sí, es, vivir en autonomía y se construye, y ¿Cómo se hace eso? Se hace sembrando la milpa, respetando a la madre tierra, cuidando y defendiendo nuestro territorio, tener nuestro propio sistema de educación, de salud, de nuestro propio sistema de justicia [...]. Cuando hablamos de vivir en y construir la autonomía, no es, un fragmento de un modo de vida, sino, es la total integralidad de la vida de un pueblo como el nuestro, las y los tsotsiles” (Comunicado, 22 de julio del 2014) 
Dicho programa implica para Las Abejas una transformación integral del modo en que se vive, punto importante si tenemos en cuenta que el gandhismo plantea la desobediencia civil como un modo de llegar a una reconstrucción social integral, más allá de la crítica o desobediencia vacía. En palabras de Ameglio (2002) "él [Gandhi] planteaba la desobediencia civil como uno de los caminos para construir esta nueva cultura y realidad, hablaba no de una acción en sí misma sino del deseo de un nuevo orden social; se trataba en el fondo de la impugnación del capitalismo occidental” (pp.142). Punto este último interesante, si se tiene en cuenta que se está hablando en los dos casos de poblaciones fundamentalmente campesinas y rurales, para quienes ser independiente implica, de algún modo, volver a la tierra y alimentarse de ella para ganar independencia. Probablemente por ello, la organización es enfática en su crítica a la política asistencialista del Estado chiapaneco, que da a los indígenas despensas, ayuda monetaria, etc. y rechaza del mismo todo tipo de ayuda; asunto que, en función de su precaria capacidad adquisitiva, deja entrever el compromiso con dicho proyecto de independencia.

Como modo de construir la autonomía, han creado entidades autónomas dentro de la misma organización que buscan reemplazar los servicios prestados por el Gobierno. Las mismas forman parte de procesos de intervención política y social noviolenta (Sharp, 1988), que pretenden dar a la autonomía una dimensión concreta que permita dar una atención integral a sus necesidades. Por ello las mismas cubren aspectos pedagógicos, jurídicos, humanos, etc. Algunas de ellas son: el área de educación autónoma, el área de justicia autónoma, el área de derechos humanos, el área de noviolencia, el área de salud, entre otras (Orozco, 2014).

Por otro lado, las mencionadas acciones se han combinado con otras, tendientes al fortalecimiento y promoción de la misma, lo cual se evidencia en la utilización de métodos de acción noviolenta (Sharp, 1988) como: persuasión e intervención social, a través de radio y medios alternativos, en los que Las Abejas invitan a imitar dicho comportamiento a otros grupos indígenas; la no colaboración social, evidenciada en el boicot social selectivo a funcionarios de gobierno; la no colaboración económica, a partir del rechazo a pagar impuestos; la no colaboración política, a través del rechazo al sostenimiento de funcionarios públicos, entre otros.

\section{Memoria y noviolencia: consideraciones sobre la otra justicia}

Paralelamente a lo expuesto en párrafos anteriores y como fruto de los planteos mencionados, se produce en la organización un proceso que, resultado de la lucha por cimentar un poder alternativo ante la injusticia, tiene a la memoria como centro. A fin de explicarlo, partiremos de dos preguntas: ¿¿Puede ser la memoria, un arma de resistencia y lucha noviolenta?; y, en ese caso, ¿a quién, o a qué se resiste? 
La memoria ha sido, sin duda alguna, la herramienta que nos ha permitido como humanidad, vincularnos con el pasado. García Peñaranda (2011:1), retomando a Candau (2001), afirma: “Los seres humanos desde siempre viven en comunidad, y durante su vida van acumulando ciertos recuerdos -y olvidando otros- que componen su memoria colectiva y les permiten construir una identidad propia”. En el ejercicio del recuerdo y el olvido, nos vamos contando quiénes somos, de dónde venimos y el lugar que ocupamos en el mundo. Por ello, para muchas minorías la memoria tiene un papel preponderante; su ejercicio y su transmisión ha sido parte de un proceso de reconstrucción de la propia identidad.

Con el pueblo tsotsil, no ocurre lo contrario. A través de la lengua oral y escrita su historia se ha transmitido por generaciones hasta hoy, siendo parte fundamental de su idiosincrasia. Por otro lado, a partir de la recuperación de la memoria, los pueblos indios organizados han logrado resistir a la imagen folclorizada de sí mismos que, apuntalada en una lógica del olvido, la colonización les impuso. La organización como parte de los pueblos originarios, no está exenta de tales inquietudes; sin embargo, en ella el recuerdo cobra una dimensión adicional: recordar es hacer presente a sus antepasados, pero también a sus mártires. Su recuerdo ha permeado su quehacer político y religioso. Lo mencionado evidencia que la masacre de Acteal dejó una marca indeleble y una herida abierta en Las Abejas. ¿Qué hacer con ésta herida? ¿Cómo responder a tanta violencia?

La propuesta de la noviolencia frente a la violencia física y directa consiste, básicamente, en tener todo un repertorio de técnicas, metodologías y procedimientos de lucha no armados, pacíficos y no cruentos que sirvan de sustitutivo a la violencia, además de toda una carga argumental [...] que deslegitime el uso de la violencia (López: 2012b:18)

En este punto el recuerdo y la resistencia se articulan en acción noviolenta (Sharp, 1988), en el sentido de que el recordatorio público de la masacre deja al descubierto la impunidad por la misma. Al recordar mes a mes y año a año lo ocurrido en Acteal, se vuelve a plantear una crítica a la violencia estructural que "se ejerce de manera indirecta y no necesariamente ha de ser intencional” (López, 2012b: 19), pero puede serlo. Lo mencionado tiene como expresión concreta en la actualidad, un proceso que -en conjunto con otras organizaciones indígenas, medios libres o alternativos y ONG's-, Las Abejas han iniciado desde el 2009 y denominan "la otra justicia”, el lekilchapanel o justicia verdadera.

Su fin es servir de justicia alternativa ante la impunidad y, desde la autonomía, ofrecer con su denuncia pública, un castigo moral a quienes promueven la injusticia y la violencia; con ella se busca exponer las heridas que la violencia estructural va dejando a su paso. Por ello la otra justicia, no solo recuerda a los mártires, sino que no olvida a todos los pueblos organizados en resistencia: 
"Para nosotros la MEMORIA es indispensable, porque un pueblo sin memoria es un pueblo muerto en vida. En los diecisiete años de lucha por la justicia y verdad de la masacre de Acteal, hemos aprendido a no callarnos, y cualquier injusticia, cualquier violación a los derechos humanos que comete el Estado Mexicano contra los pueblos organizados, ahí estamos para denunciarlos. Y entonces aprendimos a no callarnos, porque quedarse callados ante cualquier injusticia y crimen, es volverse cómplices del Estado” (Comunicado 22 de Junio 2015)

En dichas acciones la organización ha buscado y encontrado, con el paso del tiempo, la solidaridad de la sociedad civil, que ha sido un importante aliado en la difusión de su mensaje y el fortalecimiento de sus vínculos con entidades nacionales e internacionales. A ello ha contribuido, además, el uso de los medios alternativos de comunicación -como la radio "Almantal Yu’un Lekilal”, páginas de Facebook y el sitio web de la organización- que, como un método de intervención social noviolenta (Sharp, 1988) han servido tanto para reforzar el impacto público de las acciones anteriormente mencionadas, como para establecer un contacto más cercano con actores sociales en el espacio regional y transregional.

Actualmente, Las Abejas siguen trabajando por la consecución plena de los procesos que hemos descrito. Éstos son el resultado de una larga reflexión que se ha nutrido con los cambios políticos, culturales y sociales, en los que se han visto inmersos. Su historia da cuenta de un compromiso con la paz; la justicia y la noviolencia que se ha sostenido, reforzado por la memoria de sus mártires, a lo largo de sus más de 22 años de vigencia. En ella, han ofrecido a sus aliados y adversarios en la lucha un reflejo de la violencia y la deshumanización del México contemporáneo, y han dado claros ejemplos, sin embargo, de que la noviolencia no es una utopía.

\section{Algunas reflexiones finales}

En principio, creemos necesario resaltar que cualquier estudio que pretenda tratar temáticas vinculadas con las resistencia indígena en Chiapas, ha de tener en cuenta que en la misma existe diversidad; de ello da cuenta la diferencia de planteos en torno a los métodos de resistencia, como a los medios y fines que cada grupo persigue. En este sentido, la multiplicidad de actores, tensiones y reconfiguraciones que ha traído aparejada la emergencia de organizaciones con raíces en los pueblos originarios dentro del panorama político mexicano, hace necesario un abordaje diferenciado. En éste, la reconstrucción histórica de procesos culturales y políticos es fundamental.

Por otro lado, creemos que lo tratado en estas páginas -que no pretenden ser conclusivas, desde luego- permite visibilizar el importante papel que juega la agencia en relación con las posturas que establecen los actores sociales implicados en empresas de resistencia. Ni la religión, ni los 
posicionamientos políticos, y tampoco la cosmovisión de los pueblos indígenas pueden, por si solas, explicar el hecho de que un grupo o colectivo, se posicione de modo noviolento ante la opresión. Por ello pensamos que, en el acercamiento a la subjetividad y en el estudio de la organización consensuada es donde pueden hallarse las claves para una comprensión situada de los móviles que sostienen su lucha.

Respecto del caso de la organización tratada, creemos que la discusión de su historia permite aseverar que la noviolencia, ha sido y es un modo vigente de lucha en la región. En el caso de Las Abejas, podemos apreciar el poder de convocatoria que la noviolencia tiene, como fuerza que permite nuclear a diversos actores sociales en la defensa de derechos humanos y culturales. Resaltamos por ello, la vigencia que las luchas noviolentas tienen hoy por hoy en México y el hecho de que, paralelamente al belicismo, existen claros ejemplos de empresas que se apuntalan en la rebeldía, el respeto a la vida y la negación de la violencia como método de lucha. Éstas, lejos de la aspiración revolucionaria armada, han intentado promover el cambio apelando a armas morales.

Resaltamos, en ese sentido, la importancia que la memoria puede tener como categoría analítica de estudio que, en conjunto con la noviolencia, se combina para, desde el recuerdo, cuestionar la violencia estructural y proponer cambios en las políticas belicistas de contención al conflicto social.

Finalmente, creemos que lo expuesto da cuenta de que la noviolencia como categoría analítica ofrece amplias posibilidades de articulación con los fenómenos de resistencia indígena. A partir de la discusión de conceptos como el de noviolencia (López, 2004) es posible visibilizar modos de política alternativos, que se apuntalan en un cuestionamiento moral del poder y comprender de modo diferenciado, la manera en que ciertos valores como: el respeto a la vida, la búsqueda de creatividad en los medios de lucha, la solidaridad, etc. se insertan en la arena política de un modo concreto a partir de acciones que buscan cuestionar al poder, intentando devolverle la capacidad circulatoria, desde la visión concreta de los diferentes organizaciones y personas de los pueblos originarios. Ello creemos, contribuirá a que también desde la aproximación teórica a dichos fenómenos se visibilicen valores y empresas que durante mucho tiempo han permanecido en un segundo plano. 


\section{Notas}

${ }^{1}$ Una primera versión de este texto fue presentada como ponencia en el "II Congreso Religiosidades y Ritualidades en el Sur de México y Centroamérica” realizado en el Centro de Estudios Superiores de México y Centroamérica (CESMECA), de la Universidad de Ciencias y Artes de Chiapas (UNICACH), que se llevó a cabo entre los días 18 al 21 de Agosto del 2015.

${ }^{2}$ Región compuesta por los municipios de: Altamirano, Las Rosas, San Cristóbal de las Casas, Teopisca, Tenejapa, Zinacantán, Aldama, Santiago el Pinar, Amatenango del Valle, Chalchihuitán, Chamula, Chanal, Chenalhó, Huixtán, Lárrainzar, Mitontic, Oxchuc y Pantelhó. Dentro de los municipios, los centros de población son mayoritariamente indígenas, a excepción de ciudades como San Cristóbal de las Casas y Teopisca, donde conviven mestizos, indígenas y extranjeros. Dentro de Chiapas, la región registra los números más altos de población indígena.

${ }^{3}$ En este punto vale la pena diferenciar, como lo hacen López (2012); Ameglio (2002), la violencia de la lucha. La primera implica un menoscabo del otro, de su capacidad de agencia y dignidad. La segunda, si bien involucra un forcejeo con el poder, no necesariamente implica a la primera. En otras palabras, se puede luchar con o sin violencia.Ejemplo de esto último son: la lucha por los derechos civiles; la lucha por la libertad de expresión, la lucha contra la violencia, etc.

${ }^{4}$ La comunidad de Acteal (centro) se ubica en una zona rural perteneciente al municipio de Chenalhó, a dos horas de la ciudad de San Cristóbal de las casas. Se encuentra colindando con Acteal zapatista, territorio gobernado por el EZLN y Acteal cabecera municipal, donde la población es de afiliación política mayoritariamente oficialista. Lo mencionado deja ver la diversidad de posicionamientos políticos en la región y permite apreciar el modo en que el enclave de la comunidad da cuenta de su modo de ubicarse espacialmente en el conflicto.

${ }^{5}$ En adelante EZLN.

${ }^{6}$ Según el Instituto Nacional de Estadística y Geografía e Informática (INEGI, 2004) más de la mitad de la población total del país, que se comunica exclusivamente en una lengua nativa, reside en Chiapas y Oaxaca; aspecto importante si se tiene en cuenta que "El conocimiento del idioma oficial del país es un indicador que aproxima el grado de integración de los pueblos indígenas a la sociedad nacional” (Ibid: 21). Según INEGI (2010) el estado se ubica en el primer lugar en relación a la proporción de población analfabeta con respecto al resto del país y en el último respecto del total de la población que asiste a la escuela. En relación a la población ocupada que no recibe ingresos, Chiapas se encuentra en el tercer lugar del país. Por otro lado, se encuentra en el primer lugar en relación a la tasa bruta de natalidad y en la cantidad de habitantes por vivienda particular habitada. Los datos citados, permiten comprender el nivel de rezago económico, educativo, etc. en el que viven muchas comunidades de la región.

${ }^{7}$ El PRI o Partido Revolucionario Institucional fue “el partido dominante en México durante más de setenta años, hasta que fue derrotado por el Partido Acción Nacional (PAN)” en el año 2000 (Paolino, 2009:322). Su accionar ha sido cuestionado en reiteradas ocasiones por los sectores ligados al zapatismo y otras organizaciones indígenas en resistencia. 
Polis, Revista Latinoamericana, Volumen 15, $N^{\circ}$ 43, 2016

${ }^{8}$ El ayuno y la oración para pedir paz o justicia, son dos de las primeras prácticas que la organización realiza y, por otro lado, son dos acciones que los muertos de Acteal se encontraban realizando en el momento de su muerte. De ahí su importancia como elemento distintivo de la organización Las Abejas frente a otras; de ahí su peso como parte de una tradición que los vincula con la resistencia de las víctimas. Ambas son prácticas que la organización conserva hasta la fecha.

${ }^{9}$ La creciente paramilitarización en Chiapas, produjo como una de sus consecuencias, el desplazamiento de habitantes de comunidades indígenas como modo de huir de la violencia armada, producto de la persecución sufrida a partir de la sospecha de que estuviesen vinculadas al EZLN. Las Abejas tuvieron un rol activo en estos eventos a partir de la promoción y dirección del “Campamento civil por la paz” que se constituyó en Acteal centro, previamente a la masacre de 1997.

${ }^{10}$ La conmemoración mensual de la masacre de Acteal, que se ha desarrollado de manera ininterrumpida hasta la fecha, cuenta con la participación de personas de diversas procedencias, tanto nacionales como internacionales. De las doce que se realizan al año la conmemoración del 22 de diciembre concentra la mayor cantidad de personas. En ella, honrando a los muertos (Sharp, 1988), se denuncia la impunidad por la masacre y se favorece el estrechamiento de vínculos con la sociedad civil.

${ }^{11} \mathrm{El}$ Coro de Acteal, es un grupo de jóvenes pertenecientes a la organización y que, aunados por la música, participan regularmente de los eventos públicos de Las Abejas, desde el año 1998 aproximadamente.

${ }^{12}$ Siglas correspondientes a la "Comisión Interamericana de Derechos Humanos.”

${ }^{13}$ El lector puede encontrar los comunicados completos de la organización Las Abejas que se tratan en el texto, en su página web: http://acteal.blogspot.mx/ . Podrá encontrar también allí, fotografías y videos que la organización ha recopilado a lo largo de los años y que dan cuenta de sus actividades principales como colectivo. 


\section{Bibliografía}

Ameglio, P. (2002), Gandhi y la desobediencia civil. México hoy, Plaza y Valdés S.A de C.V., México D.F.

Arias, A. (2008), “Pensar Acteal: verdad justicia y reconciliación”, Este país 20, $N^{\circ}$, Facultad de ciencias Políticas y Sociales UNAM, México D.F.

Barabas, A (2000) “La construcción del indio como bárbaro: de la etnografía al indigenismo”, Alteridades, 10, núm. 19, pp. 9- 20.

Bartra, A.; Otero, G. (2008), “Movimientos indígenas campesinos en México: la lucha por la tierra, la autonomía y la democracia”, en: S. Moyo, \& P. Yeros (coord.) Recuperando la tierra. El resurgimiento de movimientos rurales en África, Asia y América Latina, Consejo Latinoamericano de Ciencias Sociales, Buenos Aires, pp. 401-428. Disponible en: http:// bibliotecavirtual.clacso.org.ar/ar/libros/sursur/moyo/18BarOt.pdf

Baucells, J.; Hava, E. (2007), "Posibilidades y límites del principio de justicia universal: el caso de Acteal”, Revista de derecho penal y criminología, $2^{\mathrm{a}}$ Época, $\mathrm{N}^{\circ} 19$, UNED. Disponible en: http://e-spacio.uned.es/fez/ eserv.php?pid=bibliuned:DerechoPenalyCriminologia20074\&dsID=posibilidades.pdf

Bonfil Batalla, G. (1990), México profundo. Una civilización negada, Grijalbo, México D.F.

Centro de Derechos Humanos Fray Bartolomé de Las Casas, AC (2015), La insurgencia de los derechos humanos. Informe Frayba, Copyleft, San Cristóbal de Las Casas.

Fazio, C. (1994), Samuel Ruiz. El caminante, Ed. Espasa Calpe, México D.F.

Galtung, J. (1969), “Violence, Peace, and Peace Research”, Journal of Peace Research, Vol. 6, N 3 pp. 167-191. Disponible en: http://www.jstor.org/ stable/422690

García Peñaranda, C (2011), “La gestión social del recuerdo y el olvido: reflexiones sobre la transmisión de la memoria”, Aposta revista de ciencias sociales, $N^{\circ} 49$, Abril, Mayo y Junio, ISSN 1696-7348, http:// www.apostadigital.com/revistav3/hemeroteca/cbernard.pdf

Guillén, D. (2003), Chiapas: rupturas y continuidades de una sociedad fragmentada, Instituto Mora, México.

Hernández Navarro, L. (2012),“Acteal, impunidad y memoria”, El cotidiano, Marzo-Abril, Universidad Autónoma Metropolitana Unidad 
Polis, Revista Latinoamericana, Volumen 15, $N^{\circ}$ 43, 2016

Azcapotzalco, México D.F. Disponible en: http://132.248.9.34/hevila/ ElCotidiano/2012/no172/11.pdf

INEGI (2004), La población indígena en México, INEGI, Aguascalientes.

Ídem (2012), Perspectiva estadística Chiapas, INEGI, Aguascalientes.

Kovic, C. (1995) “Con un solo corazón: la iglesia católica, la identidad indígena y los derechos humanos en Chiapas”, en: Nash (1995) La explosión de las comunidades en Chiapas, IWGIA, Copenhague, pp. 109 - 121.

López Martínez, M. (2004), “Noviolencia para generar cambios sociales”, Polis Revista Latinoamericana, $N^{\circ}$ 9, Santiago. Disponible en: http:// polis.revues.org/7326

Ídem (2012a), Ni paz, ni guerra sino todo lo contrario. Ensayos sobre defensa y resistencia civil, Educatori, Granada.

Ídem (2012b) Noviolencia. Teoría, acción política y experiencias, Educatori, Granada.

Moreno, M.; Romero, M. (2003), “Chiapas: crónica de una paz nerviosa”, El Cotidiano, vol. 19, núm. 118, Universidad Autónoma Metropolitana Azcapotzalco, México. Disponible en http://www.redalyc.org/ articulo.oa?id=32511806

Muñoz, F.; López, M. (2000), “El re-conocimiento de la paz en la historia”, en: Muñoz, F.; López, M. (2000), Historia de la paz. Tiempos, espacios y actores, Editorial Universidad de Granada, Granada, pp.15-50.

Orozco, E. (2008), Identidades en Construcción: Etnicidad y cambio sociopolítico. Los keremetik y viniketik pertenecientes a la organización sociedad civil "Las Abejas”, Acteal Centro, Tesis de Maestría en Antropología Social, Centro de Investigaciones y Estudios Superiores en Antropología Social (CIESAS), San Cristóbal de Las Casas.

Ídem (2014), La organización Sociedad Civil “Las Abejas”. Procesos de Lucha, resistencia y educación indígena, Tesis de Doctorado en Ciencias Sociales y Humanísticas, Universidad de Ciencias y Artes de Chiapas, San Cristóbal de Las Casas, ISBN: 978-607-8410-03-3

Paolino, P. (2009), “La posición del PRI en la política mexicana”, Política y gobierno, Vol. 16, N². Disponible en: http://www.scielo.org.mx/pdf/pyg/ v16n2/v16n2a3.pdf

Robinson, S.; Tejera, H.; Valladares de la Cruz L. (coord.) (2007), Política, etnicidad e inclusión en los albores del milenio, Ed. Porrúa, México D.F.

Sandoval, E. (2010), “Las vibraciones democráticas y pacíficas del movi- 
miento indígena en América Latina”, en: Sánchez Vázquez Luis y Juan Codorníu Solé (Eds.), Movimiento asociativo y cultura de paz. Una mirada desde Andalucía. Instituto de la paz y los Conflictos, Universidad de Granada, Granada. pp. 105-130

Sharp, G. (1988), La lucha política noviolenta. Criterios y métodos, ChileAmérica CEDESOC, Santiago.

Tavanti, M. (2003), Las abejas: pacifist resistance and syncretic identities in a globalizing Chiapas, Rutledge, New York.

Touraine, A. (1997) ¿Podremos vivir juntos? Iguales y diferentes, Fondo de Cultura Económica, El Salvador, Buenos Aires, México D.F.

Recibido: 30.01.2016

Aceptado: 05.04.2016 